\title{
EMERGING ADULTS LEADERSHIP IDENTITY DEVELOPMENT THROUGH FAMILY STORYTELLING:
}

\section{A Narrative Approach}

\section{Abstract}

The purpose of this article is to introduce a narrative framework for leadership education as a lens for exploring how emerging adults make sense of their leader identity development. This narrative framework, called Communicated Narrative Sense Making (CNSM), looks at identity through storytelling processes. Emerging adults in higher education have different experiences and come to a new awareness of themselves in a context in a variety of ways. Part of this development process is establishing an identity as a leader. We propose a narrative framework as an approach for exploring the experiences and sense-making processes of leader identity development in emerging adults.

\section{Introduction}

Past leadership scholars supported the notion that individuals are born with certain qualities and attributes that contribute to leadership effectiveness (Bass, 1990; Kirkpatrick \& Locke, 1991; Stogdill, 1948). Over the years research has shifted to support leaders do not have to be born with certain qualities but argue leaders are made during childhood and adolescent development, through leadership education programs, and professional adult experiences (Brungardt, 1996; Komives, Owen, Longerbeam, Mainella, \& Osteen, 2005; Lord \& Hall, 2005). It is important for scholars and instructors in leadership education to understand how emerging adults make sense of and develop a leader identity in order prepare future leaders with the skills necessary to be successful. The goal of this article is to explore previous research on leader development and present Communicated Narrative Sense Making (CNSM) (Koenig Kellas, 2017; Koenig Kellas, \& Kranstuber Horstman, 2015) as a new theoretical framework for exploring and understanding the development of emerging adult leaders. Our purpose is not to align a narrative framework with development models that have already been established (e.g. Leadership Identity Model) but to offer CNSM as another approach for understating the phenomenon of how emerging adults construct and make sense of their leader identity.

Komives, Owen, Longerbeam, Mainella, and Osteen (2005) argue that the majority of leadership scholarship focuses on skill-building and short-term programs, "rather than on the process of how leadership capacity or leadership identity is created or changes over time" and that "understanding the process of creating a leadership identity is central to designing leadership programs and teaching leadership" (p. 594). It is our goal by introducing a narrative framework we can further understand the process of creating a leader identity to help in the development of leadership programs and instructional pedagogies in higher 
education.

For the purpose of this article, we will focus on leader identity development of emerging adults in higher education. We define emerging adults as traditional college aged students, approximately 18-25 years old (Arnett, 2001). First, we will provide a brief overview of leadership development and emerging adulthood theories. Next, family storytelling and narrative identity literature is reviewed to illustrate how storytelling can provide a context for understanding leader identity. Finally, we will present CNSM as a framework to further explore and understand how emerging adults make sense of and construct a leader identity. We believe this framework can be applied to higher education courses and leadership programs.

\section{Leadership and Development Theories}

Brungardt (1996) conducted a review of literature to explore what was known about how leaders are developed, educated, and trained; he found two main areas of focus when looking at the development of leaders, leadership development constructs and learning leadership theory. Brungardt (1996) explains, "leadership development refers to almost every form of growth or stage of development in the life cycle that promotes, encourages, and assist in one's leadership potential." (p. 83). Leadership development theory identifies four categories of a life span: (1) early childhood and adolescent development, (2) the role of formal education, (3) adult and on-the job experiences, (4) and specialized leadership education.

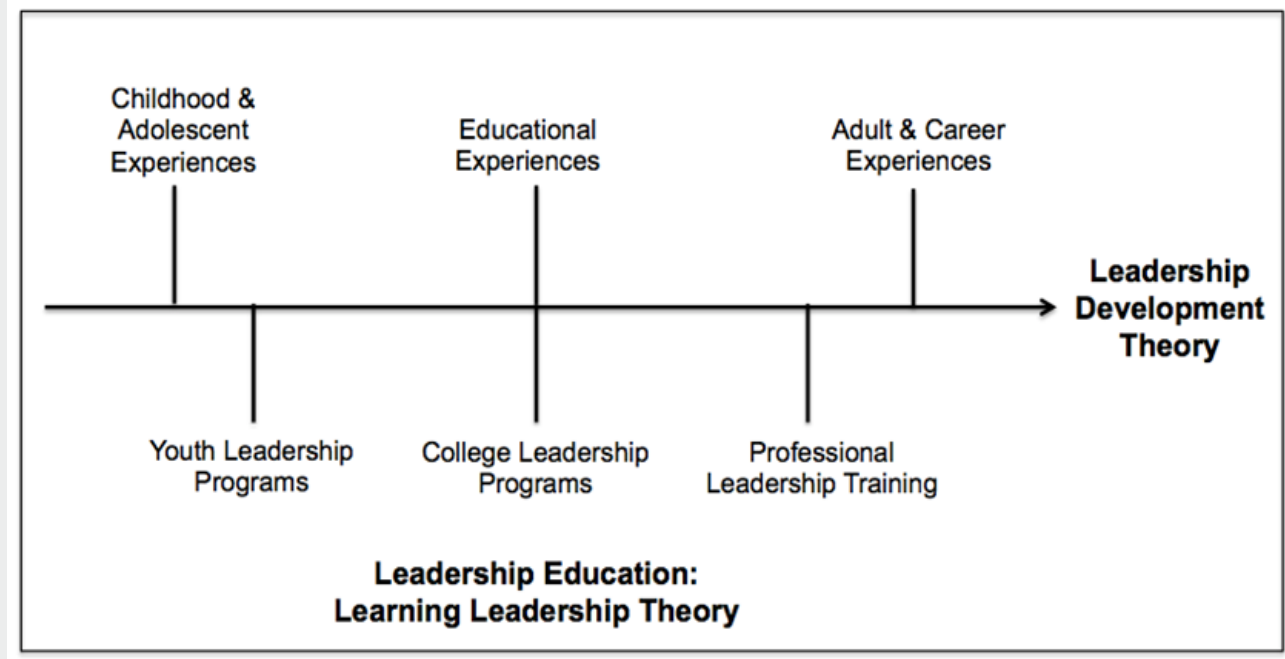

Figure 1. Life span of leader development (adapted from Brungardt, 1996).

As illustrated in Figure 1, leadership development begins in childhood/adolescence with the impact of family influences and moves into leadership education. Early research by child psychologists found personal traits (e.g. need for achievement, confidence, and assertiveness) are influenced by child/adolescent experiences and parental support
(Gardner, 1990). According to Brungardt (1996) leadership development theory brings together the human developmental process (i.e. growth from childhood to adulthood) and leadership learning theory to help educators understand best practices for teaching leadership development. 
Emerging Adulthood Theory. Understanding the human development processes of emerging adults is important for instructors in higher education. The developmental experiences and cognitive thought process of emerging adults is a period of many transitions. Arnett $(2000,2001)$ presents a theory of emerging adulthood, which focuses on ages 18-25, and argues this transitional period should neither be defined as adolescence nor a young adulthood period. This period is the age of traditional college students and it is important to understand the process an individual undergoes from late teens through their early twenties. Arnett (2000) explains, "emerging adulthood is a period of life course that is culturally constructed, not universal and immutable" (p. 470). Building on previous theoretical contributions of development (Erickson, 1968; Levinson, 1978; \& Keniston 1971) Arnett explains that adolescence and emerging adulthood is a period in which individuals take on continued role experimentations before they enter into the commitments and responsibilities of adulthood. Arnett's research shows when emerging adults are asked whether they feel they have reached adulthood, the majority of Americans in their late teens and early twenties answer in ambiguous terms. "Even in their late twenties and early thirties, nearly one third did not feel their transition to adulthood was complete." (Arnett, 2000, p. 472). To this effect, Arnett explains adolescence and adulthood are connected by a "long bridge" in which qualities most important in making the transition to adulthood are gradually attained (Arnett, 2001, p. 142).

According to Arnett's (2000) theory, identity issues in emerging adulthood can be seen in three main areas of exploration: love, work, and worldviews. Explorations of love become more serious and intimate, work experiences become more focused on preparation for adult roles, and changing worldviews start to occur during college experiences. "A college education leads to exposure to a variety of different worldviews, and in the course of this exposure college students often find themselves questioning the worldviews they brought in" (Arnett, 2001, p. 474). This provides an important foundation and responsibility for instructors in higher education in helping emerging adults to makes sense and construct their shifting worldviews.

Leadership Development Theories. When looking at the leader development of emerging adults many models have been applied. Day (2000) describes leader development as a term that conceptualizes leadership as an outcome of an entire social system where anyone can exhibit leadership. In higher education we are typically focused on developing young adults with the skills necessary to be successful in a social system. Lord and Hall (2005) propose a model of leadership skill development that goes beyond traditional discussions or training or self-directed leadership and focuses on a more long-term, slower development practice of core leadership skills. They present a model where a unique role is held by the leader's self-identity. The authors explain, "Identity is a central focus because it (a) provides an important structure around which relevant knowledge can be organize; (b) is a source of motivational and directional forces that determine the extent to which the leader voluntarily puts himself or herself in developmental situations; and (c) may provide access to personal material (i.e., stories, core values, etc.) that can be sued to understand and motivate subordinates" (p. 592).

Lord and Hall (2005) describe that an individual's leadership development progresses from novice skill domains to more expert domains. During a novice domain leaders are exploring new roles and adopt "provisional identities" which allow them to try new behaviors (p.599). This novice period could be similar to the transitional experiences of young emerging adults as described by Arnett (2000). During the intermediate level knowledge structures involve procedural skills and social domains. Leaders begin to develop more appropriate responses in unfamiliar situations. A critical aspect of sense making during the intermediate levels involves assessing appropriate social roles and conceptualizing the social situations in which specific leadership activities should be performed. These cognitive changes are integrated with an emergent identity as a leader (Lord \& Hall, 
2005). "As leadership identities develop it is also likely that individuals will be come increasingly motivated to attempt new leadership activities, creating the potential for learning new leadership skills and further identity development" (p. 602). In the final, expert stage of leadership development deep structures of personal identity and core values allows leaders to construct sophisticated understandings of situations and develop flexible leadership skills.

Lord and Hall (2005) further explain five specific skills domains associated with leadership: task, emotional, social, identity level, meta-monitoring, and value orientations. When considering identity development for the purpose of this article the model explains during the novice phase individuals differentiate themselves from others. In the intermediate phase a more relational or collective identity emerges, and finally in the expert phase a value-based identity grounded in abstract principles develops.

Lord and Hall's (2005) leadership skill development model provides insight into the development process of leaders. The model illustrates that leadership skill development occurs over an extended period of time and progresses from surface behaviors and skills, to procedural focused, and finally more value driven behaviors. Although this model does not focus on young adult development it closely aligns with human development leadership development theory. In order to understand the development process specifically of young adults we turn to work by Komives, Owen, Longerbeam, Mainella, and Osteen (2005) and their leadership identity model.

Exploring the leader development process of young adults, Komives, Owen, Longerbeam, Mainella, and Osteen (2005) used a grounded theory approach to understand the experiences in creating a leadership identity. The results of their work introduced the Leadership Identity Development (LID) model which illustrates how young adults situate themselves in the construct of leadership over time (Komives, et al. 2006). The LID model integrates six stages of leadership identity: (1) developing self-awareness, (2) exploration/engagement, (3) leader identified,
(4) leadership differentiated, (5) generativity, and (6) integration.

Each stage of leadership identity interacts with five categories that influence the development of a leadership identity: developing self, group influences, changing view of self with others, broadening views of leadership, and developmental influences. The model is based on stages explaining how individuals progress through one stage before beginning the next, however Komives, et al. (2006) explains the stages are also cyclical. Each stage is influenced by environmental factors and each individual's readiness to advance to the next stage. The model allows for stages to be repeated and in each return the individual may experience that stage with a deeper and more complex understanding.

Similar to Arnett's (2001) explanation on changing worldviews, and Lord and Hall's (2005) model of leadership development, Komives and colleagues explain as students transition through the stages they gradually shift their thoughts on what it means to be a leader. "Transitions marked a more reflective than active period" (Komives, et al., 2006, p. 405). Environmental factors and outside influences (e.g. group memberships, leadership education, mentors) were integral factors during the transition period. Specifically, developmental influences such as affirmation by adults (e.g. parents, teachers, coaches) influenced students' transition into higher leadership phases (e.g. leader identified and leader differentiated). As leadership educators strive to develop leaders for the future, it is important to understand how to advance college students into higher levels of leadership identity. However, employing such models as LID can present challenges for leadership educators.

Komives, Longerbeam, Mainella, Osteen, and Owen (2009) explain that the LID model can present challenges for assessment. The authors emphasize, it is a "misuse of developmental theory to categorize students into boxes rather than to gain insight into how they experience and interpret their world" (p. 26). Quantitative assessments of the LID model have 
have proved challenging because students may cycle themselves as leaders.

back to earlier stages when faced with challenging

situations that challenge their understanding of

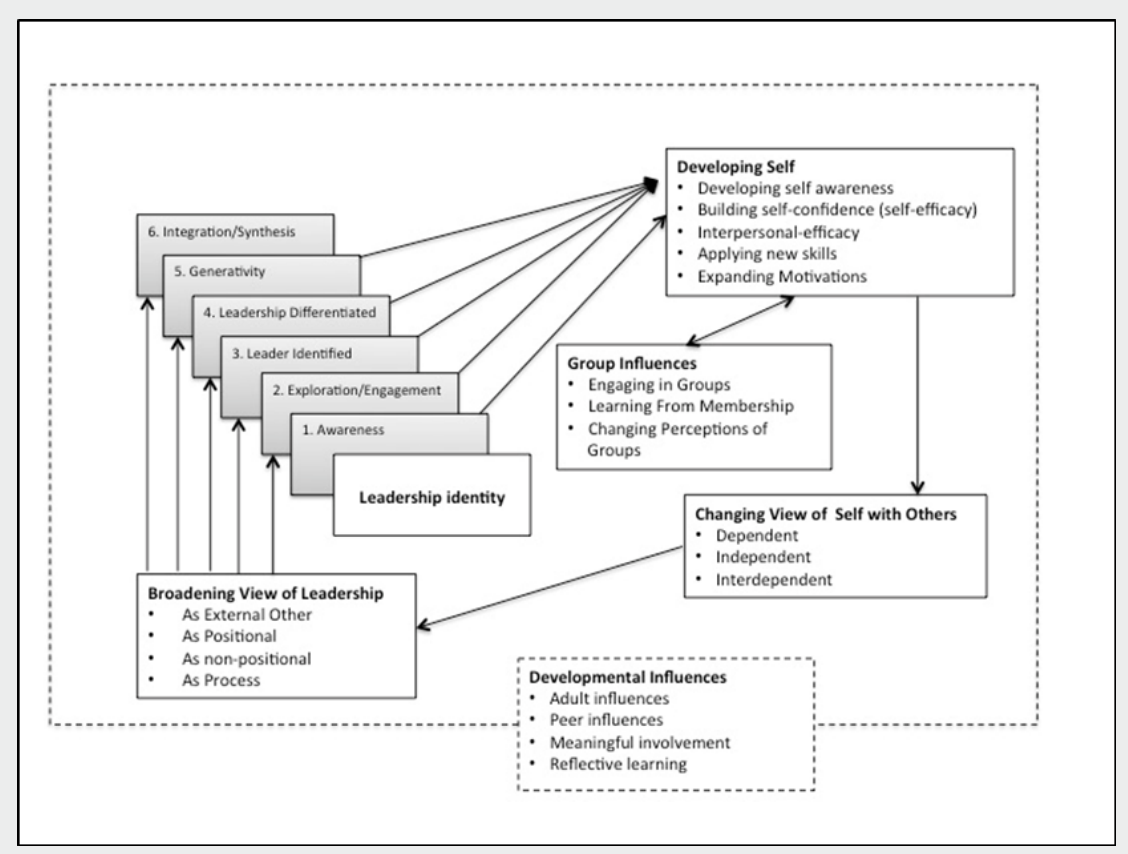

Figure 2: Leadership Identity Development Cycle (adapted from Komives et al., 2005)).

To further understand the complex phenomenon of emerging adult leader identity we provide an approach that is not limited to developmental stages. Stentz, Plano Clark, and Matkin (2012) state, "to best understand relevant leadership processes and dynamics, the field of leadership research calls for the application of multiple research approaches" (p. 1). Currently, we are addressing this call for further research approaches by conducting a phenomenological study exploring the relationship of family narratives in the construction of leader identity in young adult college students. Through this narrative framework we believe we can further explore the essence of emerging adult leader identity and further understand how young leaders make sense of leadership constructs.

In the following section we will review family storytelling and narrative identity research to bridge how leader identity development through storytelling/ narrative approaches can provide a framework for examining leader identity and further contribute to the scholarship of leadership education.

\section{Family Storytelling and Narrative Identity}

In addition to developmental models, we posit storytelling/narrative framework for exploring the phenomenon of leader identity how stories influence emerging adult development. Few examples of storytelling are found in leadership literature. For example, research has examined how leader's biographies are influential to followers and important to leadership approaches (e.g. Shamir, Dayan-Horesh, \& Adler, 2005; Sternberg, 2008), and how life stories can be used as a way to examine the development of authentic leadership styles (Sharmir \& Eilam, 2005). Human development theories explain 
emerging adults are still shaping their identities, thus rather than looking at a young leader's personal story, we propose exploring leader identity development through family socialization and the use of narratives.

Family Storytelling. Family members share in creating stories together as a way to construct individual and family identity and family culture (Koenig Kellas, 2005; Stone, 2004; Thompson, et al., 2009). Koenig Kellas (2005) states, "The content of family stories often reflects a family's values, culture, and its collective meaning" (p. 367). In this regard, we argue stories told within the family may influence values and motives that construct emerging adult's leader identity. Research on storytelling in the family has provided an extensive background supporting stories are a central means to understanding identity construction, family socialization, and ways to cope with difficulty (e.g. Koenig Kellas 2005; McAdams, 1993; Stone, 2004). Stone (2004) postulates that the family is our first culture and through family stories individuals learn the norms, rules and policies of the family. Stone goes on to state, "all children in all families stumble into their designated roles, but through family stories they are coached and encouraged, and they often grow into the costume so that it becomes a second skin" (p. 87).

Thompson et al. (2009) examined how intergenerational storytelling affects individual and family identity and how young adults take away lessons learned from these stories. The research explored how young adults embrace or reject family legacy stories and how they shape individual and family identity. Results showed participants are more likely to recall positive family legacies. Positive legacy stories included categories/themes of hardworking, caring for others, and family cohesion. Family legacy stories may be especially important in everyday life during emerging adulthood. McAdams (1993) explains, "From adolescence onward we face this task of creating an integrative life story though which we are able to understand who we are and how we fit into the adult world" (p. 91).

Kranstuber Horstman (2013) noted, "it is likely the way in which one's family approaches stories will impact the exposure to and the lessons learned from their family stories" (p. 60). Thus, we believe how stories of leadership are approached in the family will impact the meaning making of leadership constructs for young adult leaders. In considering family legacy stories and lessons learned through them, stories told within the family unit might influence leadership qualities in emerging adults and impact the ways in which a leader identity is developed. In addition, how emerging adults make sense of these stories may influence the ways in which they construct approaches to leadership.

Narrative Identity. Research on narrative identity explains, all humans are storytellers (Fisher, 1987) and we come to understand who we are by creating a story of the self (McAdams, 1993). McAdams (1993) explains individuals select the most important or significant life events to develop as stories which help create and shape their (narrative) identity. According to McAdams' theory of narrative identity, family storytelling becomes important to identity development, specifically in young adults. As children develop into adolescents and into adulthood they begin to establish their own motivational patterns. These patterns of desire are reflected thematically in their personal myths (McAdams, 1993). The theory contends individuals first become "selfconscious mythmakers" in late adolescent years when faced with issues of identity. "Therefore, the transition from adolescence to young adulthood is an especially significant phase in the development of human identity" (McAdams, 1993, p. 36). Supported by leadership development theories, the transitions young adults experience is critical in developing and understanding an identity as a leader.

For example, we can see this in the later stages of leader identity development, such as the generativity stage (i.e. stage five) in the LID model. Generativity is defined as, "primarily the concern in establishing and guiding the next generation" (Erikson, 1950, 1963, p. 267). Students who demonstrate generative action show tangible behaviors that promote the well being 
of future generations (de St. Aubin \& McAdams, 1995). In the generativity phase, adults as mentors and meaning making were key factors during the transition. McAdams and de St. Aubin (1998) suggest identity development is something that is constructed and reconstructed throughout a person's adult life through narration, and the "generativity script" is one piece of that life narration (p. 12). McAdams (2001) further supports the field of generativity could be expanded by understanding why some people become more generative than others and what childhood and adolescent experiences can be linked to stronger generativity. To assist those in leadership education research, we present Communication Narrative Sense-Making as a new framework to further understand and explore how narratives may provide a window for leader identity development.

\section{Communication Narrative Sense- Making}

Koenig Kellas and Kranstuber Horstman (2015) present Communicated Narrative Sense-Making (CNSM) as an empirical approach to understanding the ways in which narratives and storytelling affect and reflect individual and relational well being in the family. The authors posit CNSM explores the communicated nature of narratives and therefore the content or processes of telling stories in families. Koenig Kellas (2017) explains, most narrative theorizing is grounded in an interpretive framework using rich, qualitative, subjective meaning. CNSM puts communication as the center focus by defining storytelling as, "the communicative manifestation of narrative sense-making" (Koenig Kellas, 2017, p. 3).

CNSM is founded on the assumption that narratives serve three primary functions, which help people make sense of and organize experiences of family life: creating, socializing, and coping (Koenig Kellas \& Kranstuber Horstman, 2015). Creating is narratively communicating and reflecting individual, relational, and family identity (e.g. McAdams, 1993; Bamberg, 2011). Another function of family narratives is socializing which is teaching lessons and/or socializing family members to specific values, assumptions and behaviors (e.g. Miller-Day \& Dodd, 2004; Stone, 2008). Finally, coping is the process of making sense of and dealing with stress, difficulty, illness, trauma, and/or loss (e.g. Frank, 1997.).

Koenig Kellas and Kranstuber Horstman (2015) further organize CNSM into three heuristics to understanding the construction of meaning through a communicative lens: retrospective storytelling, interactional storytelling, and translational storytelling. Retrospective storytelling is an approach to research on participants' recollections of storytelling in the family that affects and reflects family socialization. Interactional storytelling is research that examines the interactional nature of (joint) storytelling in families as it links to individual and relational behaviors that distinguish the way we communicate stories. Translational storytelling is an approach to narrative research that examines how storytelling can inform translational or interventionist efforts to help families cope with difficulty. Figure 3 illustrates the three heuristics and provides and example of how each storytelling approach can be applied to leadership education.

We propose leadership educators can apply the CNSM framework along with leadership development models to understand developmental influences of emerging adults. For example, scholarship and educational pedagogy could explore the CNSM functions of creating (i.e. identity), socializing (i.e. values, assumptions and behaviors) and coping (i.e. major life transitions) through any of the three heuristics to understand how young adults make sense of and come to understand their identity as a leader. As supported by leadership development theory and the LID model, developmental factors such as adult influences (e.g. stories told by parents and mentors) help emerging adults transition into higher stages of leadership development (e.g. generativity). 


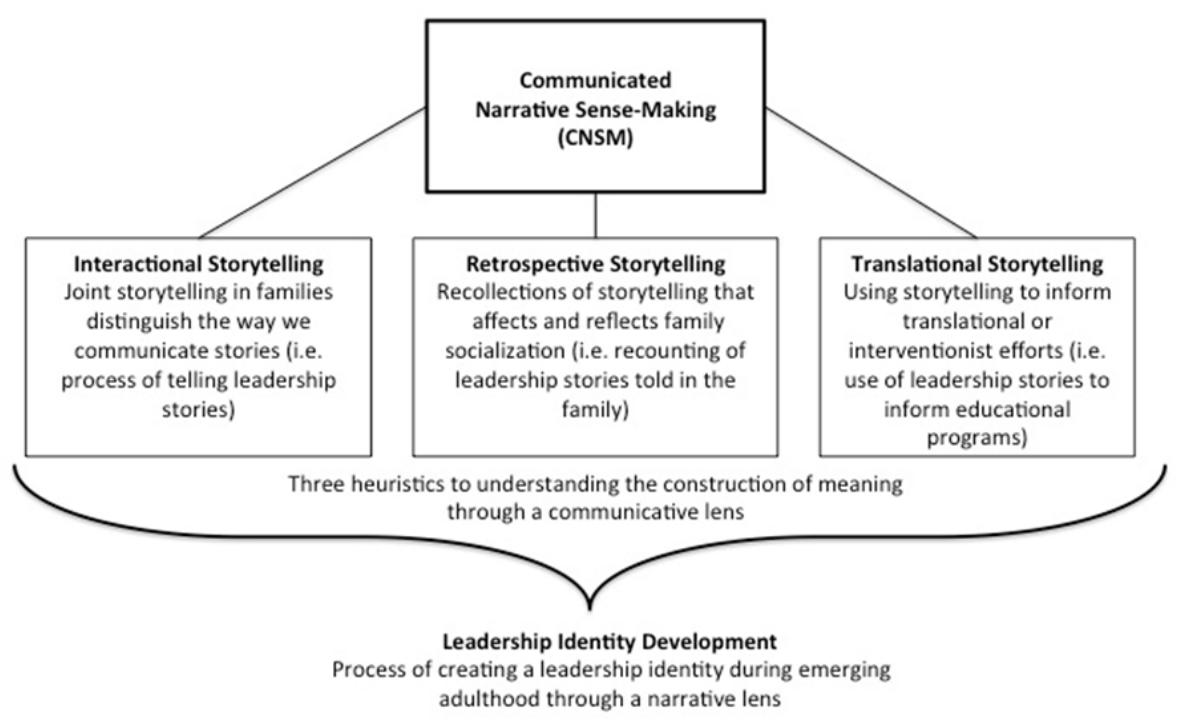

Figure 3: Leadership identity development through a CNSM approach (adapted from Koenig Kellas \& Kranstuber Horstman, 2015)

Research using a retrospective storytelling method may be used to examine how the recollection of specific family stories influence emerging adults' leader identity. "Family stories in the retrospective storytelling tradition represent stories that are told to socialize and unite family members under a common history and set of expectations about the world and the family itself" (Koenig Kellas \& Kranstuber Horstman, 2015, p. 83). Research may also take an interactional approach to examine how the process of jointly telling leadership stories affects the developmental process of creating a leader identity. The use of storytelling may also be used for translational research in developing educational programs and instructional teaching methods.

We believe future research should explore the process of leader identity development through a narrative lens to provide empirical data on the uses and applications of this approach. The CNSM approach provides a unique perspective for understanding how identity is created and socialized through the process of telling and recounting stories told within the family. Our current research agenda explores how retrospective family narratives influence leader identity of young adults in college. Our goal is to share our findings with leadership educators to help in designing leadership pedagogy.

\section{Implications for Leadership Education}

There are multiple implications for the use of narrative approaches in leadership education. One implication is to provide intersectionality across a multitude of dimensions that impact identity. Komives, Longerbeam, Mainella, Osteen, and Owen (2009) state, "leadership educators must acknowledge the ways leadership identity intersects with other dimensions of identity such as race, culture, sexual orientation, gender, disability, religion, and social class" (p. 24). Work on Social Identity Theory (Tajfel \& Turner, 1986) affirms our social identity stems from a cognitive and emotional identification within our social groups: culture, race, age, religion, vocation, and political affiliation. Hogg (2001) explains "leadership dynamics may be significantly affected by the social cognitive processes associated with group membership (and group behaviors)" (p. 186). Just as familial stories influence socialization and identity, the jointly told stories within a group may influence the sense making of a leader's identity. Day and 
Harrison (2007) also argue, there is an increasing need to understand how leadership might be constructed more collectively through multi-level approaches to leadership development. Table 1 provides examples for applying narrative work into leadership courses.

Table 1.

Frequency of Respondent Perceptions.

\begin{tabular}{|c|c|c|c|}
\hline Activity & Description & CNSM function & CNSM framework \\
\hline Journaling & $\begin{array}{l}\text { Students keep reflective } \\
\text { journals over the course of the } \\
\text { semester to reflect on: } \\
\text { - identity development, } \\
\text { - socialization of group } \\
\text { norms, } \\
\text { - coping with periods of } \\
\text { transition }\end{array}$ & $\begin{array}{l}\text { Identity Construction } \\
\text { Socialization } \\
\text { Coping }\end{array}$ & $\begin{array}{l}\text { Retrospectively } \\
\text { recounting stories } \\
\text { Translational results } \\
\text { of findings }\end{array}$ \\
\hline Leader Interviews & $\begin{array}{l}\text { Students interview an adult } \\
\text { they see as a leader and report } \\
\text { how that leader has influenced } \\
\text { their leader identity }\end{array}$ & Identity Construction & $\begin{array}{l}\text { Interactional } \\
\text { Storytelling }\end{array}$ \\
\hline Identity Stories & $\begin{array}{l}\text { Students share their leader } \\
\text { identity story }\end{array}$ & Identity Construction & $\begin{array}{l}\text { Retrospectively } \\
\text { recounting stories }\end{array}$ \\
\hline
\end{tabular}

\section{Conclusions}

Leadership development theory has supported early adolescent development, educational programs, and adult experiences aid in the development of a leader's identity. Although leadership research has applied storytelling to the effects it has on followers and authentic leadership styles, it has not applied a narrative lens to understanding how stories are influential during the emerging adult phases of creating a leader identity. One way to explore the phenomenon of leader identity development is through a CNSM storytelling framework. We believe by applying a storytelling approach scholars and educators will gain a deeper understanding into how stories help emerging adults create and make sense of their identity as a leader.

Future research on leader identity development may also move toward translational narrative research by developing courses and educational programs for developing young college students into leaders. Results from this research could produce new leadership curriculum and training programs focused on helping future leaders understand where their identity stems from and how their identity influences how they interact with others. "As our society grows larger and more complex, the need for increasing numbers of leaders at all levels of our institutions will continue to grow... Thus our task is clear: to create farreaching development and educational environments that truly foster leadership capabilities" (Brungardt, 1996, p. 91). CNSM and storytelling approaches may provide leadership educators and practitioners with the tools and knowledge needed to better develop and educate a future generation of leaders. 


\section{References}

Arnett, J. J. (2000). Emerging adulthood: A theory of development from late teens through the twenties. American Psychologist, 55(5), 469-480. doi: 10.1037//0003-066X.55.5.469

Arnett, J. J. (2001). Conceptions of the transition to adulthood: Perspectives from adolescence through midlife. Journal of Adult Development, 8(2), 133-143.

Allen, K. E., \& Cherrey, C. (2000). Systemic leadership: Enriching the meaning of our work. Lanham, MD: University Press.

Bamberg, M. (2011). Who am I? Narration and its contribution to self and identity. Theory \& Psychology 21, 3-24. doi: 10.1177/0959354309355852

Bass, B. M. (1990). Bass and Stogdill's handbook of leadership: A survey of theory and research. New York: Free Press.

Brungardt, C. (1996). The making of leaders: A review of the research in leadership development and education. Journal of Leadership Studies, 3(3), 81-95. doi: 10.1177/107179199700300309

Day, D. V., \& Harrison, M. M. (2007). A multilevel, identity-based approach to leadership development. Human Resource Management Review, 17, 360-373

De St. Aubin, E., \& McAdams, D. P. (1995). The relations of generative concern and generative action to personality traits, satisfaction/happiness with life, and ego development. Journal of Adult Development, 2 , 99 - 112. doi: 10.1007/BF02251258

Erikson, E. H. (1950, 1963). Childhood and society. New York: Norton.

Erikson, E. H. (1968). Identity: Youth and crisis. New York: Norton.

Fisher, W. R. (1987). Human communication as narration: Toward a philosophy of reason, value and action. Columbia, SC: University South Carolina Press.

Frank, A. (1997). The wounded storyteller: Body, illness, and ethics. Chicago, IL: University Chicago Press.

Gardner, J. W. (1990). On leadership. New York: The Free Press.

Hogg, M. A. (2001). A social identity theory of leadership. Personality and Social Psychology Review, 5(3), 184-200. Doi: 10.1207/S15327957PSPR0503_1

Keniston, K. (1971). Youth and dissent: The rise of a new opposition. New York: Harcourt Brace Jovanovich.

Kirkpatrick, S. A. \& Locke, E. A. (1991). Leadership: Do traits matter? The Executive, 5, 48-60.

Koenig Kellas, J. (2005). Family ties. Communicating identity through jointly told family stories. Communication Monographs, 72, 365-389. doi: 10.1080/03637750500322453

Koenig Kellas, J. (2017). Communicated Narrative Sense-Making Theory: Linking storytelling and health. In D. O. Braithwaite, E. Suter, \& K. Floyd (Eds.) Engaging theories in family communication, 2nd ed. New York: Routledge. 


\section{References}

Koenig Kellas, J., \& Kranstuber Horstman, H. (2015). Communicated narrative sense-making. In L.H. Turner, \& West (Eds). The Sage Handbook of Family Communication (pp. 76-90). Los Angeles, CA: Sage.

Komives, S. R., Lucas, N., \& McMahon, T. R. (1998). Exploring leadership: For college students who want to make a difference. San Francisco, CA: Jossey-Bass.

Komives, S. R., Owen, J. E., Longerbeam, S. D., Mainella, F. C., \& Osteen, L. (2005). Developing a leadership identity: A grounded theory. Journal of College Student Development, 46, 593-611. doi: 10.1353/ csd.2005.0061

Komives, S. R., Longerbeam, S. D., Owen, J. E., Mainella, F. C., \& Osteen, L. (2006). A leadership identity development model: Applications from a grounded theory. Journal of College Student Development, 47(4), 401-418. doi: 10.1353/csd.2006.0048

Komives, S. R., Longerbeam, S. D., Mainella, F., Osteen, L., \& Owen, J. E. (2009). Leadership identity development: Challenges in applying a developmental model. Journal of Leadership Educaiton, 8, 12-47

Kranstuber Horstman, H. (2013). "Love stories aren't always like the movies": The relational implications of inheriting parents' courtship stories. In J. Koenig Kellas (Ed.), Family storytelling: Negotiating identities, teaching and meaning making (pp. 57-78). New York: Taylor and Francis

Levinson, D. J. (1978). The seasons of a man's life. New York: Ballantine.

Lord, R. G., \& Hall, R. J. (2005). Identity, deep structure and the development of leadership skill. The Leadership Quarterly, 16, 591-615. doi:10.1016/j.leaqua.2005.06.003

McAdams, D. P. (1993). Stories we live by: Personal myths and the making of the self. New York, NY: Guildord.

McAdams, D. P., \& de St. Aubin, E. (1998). Epilogue: Emerging themes and future directions. In D. P. McAdams \& E. de St. Aubin (Eds.), Generativity and adult development (pp. 483-490). Washington, DC: American Psychological Association.

Miller-Day, M., \& Dodd, A. H. (2004). Toward a descriptive model of parent-offspring communication about alcohol and other drugs. Journal of social and Personal Relationships, 2(1), 69-91. doi: $10.1177 / 0265407504039846$

Shamir, B., Dayan-Horesh, H., \& Adler, D. (2005). Leading by biography: Towards a life-story approach to the study of leadership. Leadership, 1(13), 13-29. doi: 10.1177/1742715005049348

Shamir, B. \& Eilam, G. (2005). "What's your story?" A life-stories approach to authentic leadership development. Leadership Quarterly, 16, 395-417. doi:10.1016/j.leaqua.2005.03.005

Stentz, J. E., Plano Clark, V. L., \& Matkin, G. S. (2012). Applying mixed methods to leadership research: A review of current practices. The Leadership Quarterly, 23(6), 1173-1183. doi: 10.1016/j. leaqua.2012.10.001

Sternberg, R. J. (2008). The WICS approach to leadership: Stories of leadership and structures and processes that support them. The Leadership Quarterly, 19, 360-371. doi: 10.1016/j.leaqua.2008.03.008 


\section{References}

Stogdill, R. M. (1948). Personal factors associated with leadership: A survey of the literature. Journal of Psychology, 25, 35-71. doi: 10.1080/00223980.1948.9917362

Stone, E. (2004). Black sheep and kissing cousins: How our family stories shape us. New Brunswick, NJ: Transaction Publisher.

Thompson, B., Koenig Kellas, J., Soliz, J., Thompson, J., Epp, A., \& Schrodt, P. (2009). Constructing individual and family identity through intergenerational storytelling. Narrative Inquiry, 19(1), 106-134. doi:10.1075/ ni.19.1.07tho

Zimmerman-Oster, K., \& Burkhardt, J. C. (1999). Leadership in the making: A comprehensive examination of the impact of leadership development programs on students. The Journal of Leadership Studies, 6, 50-66. doi:10.1177/107179199900600304 